\title{
Low risk of attrition among adults on antiretroviral therapy in the Rwandan national program: a retrospective cohort analysis of 6,12 , and 18 month outcomes
}

Harriet Nuwagaba-Biribonwoha ${ }^{1,2^{*}}$, Aleksandra Jakubowski ${ }^{1}$, Veronicah Mugisha', Paulin Basinga ${ }^{3}$, Anita Asiimwe $^{4}$, Denis Nash ${ }^{5}$ and Batya Elul ${ }^{1,2}$

\begin{abstract}
Background: We report levels and determinants of attrition in Rwanda, one of the few African countries with universal ART access.

Methods: We analyzed data abstracted from health facility records of a nationally representative sample of adults [ $\geq 18$ years] who initiated ART 6, 12, and 18 months prior to data collection; and collected facility characteristics with a health facility assessment questionnaire. Weighted proportions and rates of attrition [loss to follow-up or death] were calculated, and patient- and health facility-level factors associated with attrition examined using Cox proportional hazard models.

Results: 1678 adults initiated ART 6, 12 and 18 months prior to data collection, with 1508 person-years [PY] on ART. Attrition was 6.8\% [95\% confidence interval [CI] 6.0-7.8]: 2.9\% [2.4-3.5] recorded deaths and 3.9\% [3.4-4.5] lost to follow-up. Population attrition rate was 7.5/100PY [6.1-9.3]. Adjusted hazard ratio [aHR] for attrition was 4.2 [3.0-5.7] among adults enrolled from in-patient wards [vs 2.2 [1.6-3.0] from PMTCT, ref: VCT]. Compared to adults who initiated ART 18 months earlier, aHR for adults who initiated ART 12 and 6 months earlier was 1.8 [1.3-2.5] and 1.3 [0.9-1.9] respectively. Male aHR was 1.4 [1.0-1.8]. AHR of adults enrolled at urban health facilities was 1.4 [1.1-1.8, ref: rural health facilities]. AHR for adults with CD4+ $\geq 200$ cells/ $/ \mathrm{L}$ vs $<200$ cells/ $\mu \mathrm{L}$ was 0.8 [0.6-1.0]; and adults attending facilities with performance-based financing since 2004-2006 [vs. 2007-2008] had aHR 0.8 [0.6-0.9].
\end{abstract}

Conclusions: Attrition was low in the Rwandan national program. The above patient and facility correlates of attrition can be the focus of interventions to sustain high retention.

Keywords: Antiretroviral therapy [ART], Retention, Attrition, Mortality, Loss to follow-up, Rwanda

\section{Background}

Millions of HIV-infected adults have initiated antiretroviral therapy $[\mathrm{ART}]$ in the past decade, but the overall impact of these programs can be compromised by patient attrition, including death and loss to follow-up [1-8]. Rwanda is one of a handful of African countries to have

\footnotetext{
* Correspondence: hn2158@columbia.edu

'ICAP, Columbia University, Mailman School of Public Health, New York, New York, USA

${ }^{2}$ Department of Epidemiology, Mailman School of Public Health, Columbia University, New York, New York, USA

Full list of author information is available at the end of the article
}

achieved universal ART access, with at least $80 \%$ of the people eligible for ART receiving it $[9,10]$. ART services in Rwanda were established in 2002, and by 2012, over 100,000 HIV-infected patients had initiated ART at more than 400 health facilities [11,12]. High levels of retention on ART were reported for the first few years of the national program $[13,14]$; indeed, in a nationally representative study conducted in $2004-2005,92 \%$ and $86 \%$ of patients who initiated ART 6 and 12 months earlier, respectively, were alive and on ART at the health facility of ART initiation [13]. Over time, the national program

\section{Ciomed Central}

(c) 2014 Nuwagaba-Biribonwoha et al.; licensee BioMed Central Ltd. This is an Open Access article distributed under the terms of the Creative Commons Attribution License (http://creativecommons.org/licenses/by/4.0), which permits unrestricted use, distribution, and reproduction in any medium, provided the original work is properly credited. The Creative Commons Public Domain Dedication waiver (http://creativecommons.org/publicdomain/zero/1.0/) applies to the data made available in this article, unless otherwise stated. 
expanded significantly, with over a five-fold increase in the number of facilities providing ART and the number of patients initiating ART [12]. As Rwanda, continues to build sustainable ART programs, it is important to continually assess whether these high levels of retention can be sustained with program scale-up and universal ART access. We use data from a nationally representative study of adults initiating ART to report on levels and correlates of attrition.

\section{Methods}

\section{Study design and data collected}

The data presented here were collected between September 2008 and April 2009 as part of a nationally-representative study of adherence among adults on ART. The full methods have been described elsewhere [15], but briefly multi-stage sampling was used to select 1,798 adults who had initiated ART approximately 6,12 and 18 months prior to data collection across 20 HIV health facilities from the total of 9,693 adults receiving ART at 113 health facilities in Rwanda at the time of sampling (Figure 1). Data from patient medical charts and pharmacy recordsincluding demographic and clinical characteristics, dates of ART initiation and health facility visits, and patient outcomes-were abstracted by trained study personnel using a structured tool. A health facility assessment questionnaire captured information on characteristics of each of health facility including the type and location of the health facility in which HIV services were located, availability of supportive services for ART patients e.g. home visits and timing of the introduction of performance based financing. In this setting, performance based financing was a supply-side intervention that provided health facilities a payment mechanism based on fees for services (conditional on quality) to motivate health workers to increase quality health outputs. Key HIV

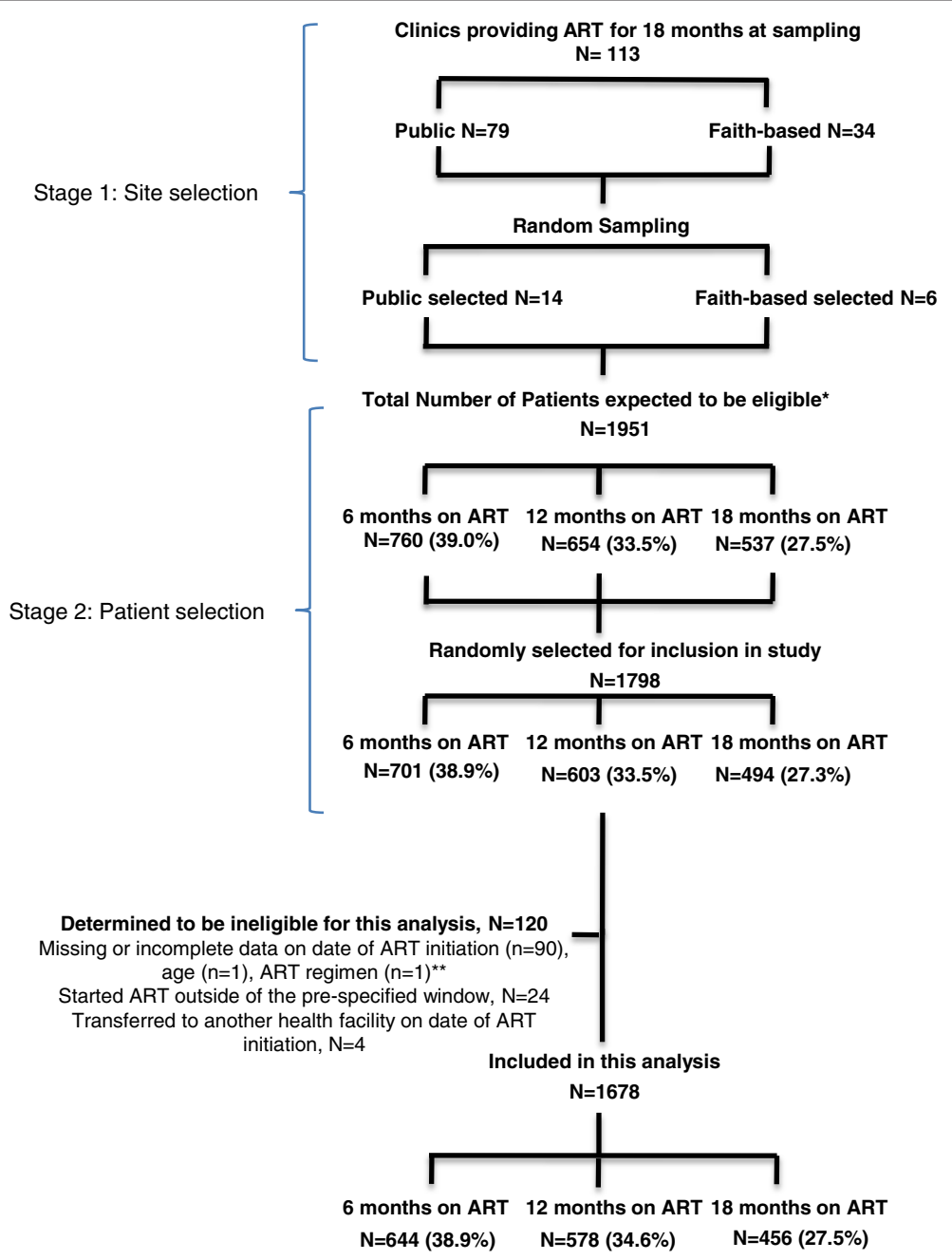

Figure 1 Sampling and participant selection. *Data obtained from TRACNet, the national monitoring and evaluation system. ${ }^{*}$ Data not found in clinic records at the time of data abstraction. 
indicators (like number of patients tested for HIV, number of patients newly initiating ART) were rewarded with financial incentives and infrastructural support. We hypothesized those facilities that had performance based financing for longer would be motivated to ensure better health outcomes among patients, including retention.

\section{Inclusion criteria}

During the study period the national adult ART initiation criteria in Rwanda were CD $4<200$ cells $/ \mu \mathrm{L}$ or WHO stage IV, with stavudine and zidovudine as the main nucleoside reverse-transcriptase inhibitors used in first line ART regimens [16]. Patients sampled for the study described above were eligible for this analysis if they were 18 years or older, and had initiated first-line ART at one of the study facilities 6, 12, and 18 months [+/- 2 months] prior to data collection or transferred into one of the study facilities within 30 days of ART initiation. We aimed to determine the population estimate of attrition by conducting secondary analysis of an existing dataset, using the entire sample. Basing on Lowrance et al's estimates of death and lost to follow-up, we determined that a dataset of 1798 would allow detection of attrition between $5 \%$ and $7 \%$ with $>90 \%$ power and $5 \%$ precision. Of the 1798 adults originally sampled, 120 were excluded as they started ART outside of the abovespecified timeframe $[n=24]$, were missing information on the date of ART initiation [ $=90]$, ART regimen $[\mathrm{n}=1]$, and age [ $n=1]$, or transferred to another health facility on the same day as starting ART [n=4], resulting in a final analytic sample of 1678 adults (Figure 1).

\section{Outcome}

The outcome for this analysis was attrition, which included patients who were known to have died and those who were lost to follow-up [LTF]. Adults were considered LTF if they were not known to have died or transferred to another health facility and had not made a clinical or pharmacy visit in the 90 days before data abstraction. Adults were considered retained on ART if they picked up ART in the 90 days preceding data abstraction. Adults who were recorded as transferring out to another health facility were reported in a separate category, and not included in the retained or attrition outcomes.

\section{Statistical methods}

Statistical analysis was conducted using Stata software version 12.1 [StataCorp. 2011. Stata Statistical Software: Release 12. College Station, TX: StataCorp LP]. Survey procedures, including finite population correction, were used to adjust estimates for the complex survey design. We applied sampling weights that took into account the probability of a health facility being selected from the
113 health facilities providing ART at the time of sampling and the probability of a participant being selected from all adults who initiated ART at 6,12 and 18 months previously, and thus results presented in this paper represent population-wide estimates of attrition. Descriptive statistics were computed for patient- and health facilitylevel characteristics. We calculated the proportion and rates per 100 person years [PY] of attrition for the entire population and by time on ART [i.e. 6, 12 and 18 months], and the 95\% confidence interval around these estimates. Adults who transferred to another health facility were censored at the date of transfer.

Patient- and health facility-level factors associated with attrition were modeled using weighted data in bivariate and multivariable Cox proportional hazard models to calculate crude and adjusted hazard ratios and 95\% confidence intervals. Variables included in the model were pre-selected according to hypothesised relevance and data availability, excluding variables that were collinear or lacked heterogeneity. We aggregated adults who had initiated ART 6, 12, and 18 months prior to data collection to increase statistical power, and controlled for time since ART initiation in the multivariable model.

\section{Ethical considerations}

The study protocol was approved by the Rwanda National Ethics Committee and the Institutional Review Board at Columbia University. This study was funded through the President's Emergency Plan for AIDS Relief [PEPFAR] through the Centers for Disease Control and Prevention [CDC] and received Associate Director of Science [ADS] clearance. This analysis was based on data collected by abstraction from existing medical records; individuallevel patient consent was waived by all approving ethical boards, and not sought.

\section{Results}

A total of 1678 adults were included in this analysis, 644 [37.4\%], 578 [33.3\%], and 456 [29.3\%] who had initiated ART 6, 12 and 18 months prior to data collection, respectively. The total amount of follow-up time was 1508 person years, while the average follow-up time was 11.3 months. The weighted population was 8,373, 3123 [37.3\%], 2762 [33.0\%], and 2488 [29.7\%] patients who had initiated ART 6, 12 and 18 months prior to data collection respectively, and represented $86.4 \%$ of the sampling frame population of 9,693.

Table 1 shows the characteristics of the population on ART. Median age of the population at ART initiation was 36 years [IQR $30-43$ ] and $64.6 \%$ were female. Over two thirds [69.0\%], were enrolled into the ART program from voluntary counseling and testing [VCT] services, while $14.6 \%$ enrolled from PMTCT services and $4.9 \%$ from in-patient wards. The majority [63.6\%] were classified as 


\begin{tabular}{|c|c|c|c|c|c|c|c|c|c|c|}
\hline & & & \multicolumn{7}{|c|}{ Time on ART prior to data collection } \\
\hline & & \multirow{2}{*}{\multicolumn{2}{|c|}{$\begin{array}{c}\begin{array}{c}\text { Overall } \\
\text { (all adults) }\end{array} \\
n=1,678 \\
\end{array}$}} & \multirow{2}{*}{\multicolumn{2}{|c|}{$\begin{array}{c}6 \text { months } \\
\text { on ART } \\
n=644\end{array}$}} & \multirow{2}{*}{\multicolumn{2}{|c|}{$\begin{array}{c}12 \text { months } \\
\text { on ART }\end{array}$}} & \multirow{2}{*}{\multicolumn{2}{|c|}{$\begin{array}{c}18 \text { months } \\
\text { on ART }\end{array}$}} & \multirow[t]{3}{*}{$p$-value } \\
\hline & & & & & & & & & & \\
\hline & & $\mathrm{N}$ & Weighted \% & $\mathbf{N}$ & Weighted \% & $\mathrm{N}$ & Weighted \% & $\mathrm{N}$ & Weighted \% & \\
\hline \multicolumn{11}{|l|}{ Patient-level characteristics } \\
\hline \multirow[t]{4}{*}{ Age groups } & $18-25$ years & 200 & 10.7 & 61 & 8.4 & 76 & 12.1 & 63 & 12.1 & \\
\hline & $26-35$ years & 619 & 35.5 & 229 & 33.8 & 210 & 34.8 & 180 & 38.4 & \\
\hline & $36-45$ years & 562 & 33.8 & 227 & 36.4 & 185 & 32.4 & 150 & 32.2 & \\
\hline & $46+$ years & 297 & 20.0 & 127 & 21.5 & 107 & 20.7 & 63 & 17.3 & 0.010 \\
\hline \multirow[t]{2}{*}{ Gender } & Female & 1079 & 64.6 & 414 & 64.2 & 380 & 65.9 & 285 & 63.8 & \\
\hline & Male & 229 & 35.4 & 229 & 35.8 & 195 & 34.1 & 170 & 36.2 & 0.361 \\
\hline \multirow[t]{4}{*}{ Source of referral to ART clinic } & $V C T^{a}$ & 1157 & 69.0 & 460 & 70.6 & 400 & 68.4 & 297 & 67.7 & \\
\hline & PMTCT ${ }^{\mathrm{b}}$ & 282 & 14.6 & 102 & 14.6 & 92 & 14.1 & 88 & 15.2 & \\
\hline & In-patient ward & 70 & 4.9 & 21 & 4.0 & 20 & 4.1 & 29 & 6.9 & \\
\hline & Other ${ }^{c}$ & 169 & 11.5 & 61 & 10.8 & 66 & 13.4 & 42 & 10.2 & 0.172 \\
\hline \multirow[t]{3}{*}{ WHO stage at ART initiation ${ }^{d}$} & Stage | and || & 1019 & 63.6 & 448 & 71.7 & 320 & 60.5 & 251 & 56.8 & \\
\hline & Stage III & 559 & 32.7 & 163 & 25.5 & 218 & 35.4 & 178 & 39.0 & \\
\hline & Stage IV & 65 & 3.7 & 20 & 2.8 & 26 & 4.1 & 19 & 4.3 & $<.001$ \\
\hline \multirow{3}{*}{$\begin{array}{l}\text { CD4+ count (cells } / \mu \mathrm{L}) \\
\text { at ART initiation }\end{array}$} & $0-199$ & 689 & 37.1 & 180 & 25.7 & 273 & 42.1 & 236 & 46.0 & \\
\hline & $200+$ & 753 & 47.8 & 357 & 58.1 & 236 & 45.3 & 160 & 37.5 & \\
\hline & Missing & 236 & 15.1 & 107 & 16.3 & 69 & 12.6 & 60 & 16.5 & $<.001$ \\
\hline \multirow[t]{3}{*}{ Initial ART regimen containing... } & Stavudine & 942 & 58.9 & 184 & 34.1 & 387 & 65.3 & 371 & 83.3 & $<.001$ \\
\hline & Zidovudine & 731 & 40.9 & 459 & 65.8 & 188 & 34.1 & 84 & 16.6 & \\
\hline & Tenofovir & 5 & 0.2 & 1 & 0.1 & 3 & 0.6 & 1 & 0.1 & \\
\hline \multicolumn{11}{|l|}{ Characteristics of clinic attended } \\
\hline \multirow[t]{2}{*}{ Location } & Rural & 599 & 50.0 & 215 & 47.6 & 221 & 53.6 & 163 & 49.1 & \\
\hline & Urban & 1079 & 50.0 & 429 & 52.4 & 357 & 46.4 & 293 & 50.9 & 0.781 \\
\hline \multirow[t]{2}{*}{ Facility level } & Health center & 914 & 64.2 & 349 & 63.8 & 326 & 66 & 239 & 62.5 & \\
\hline & Hospital & 764 & 35.8 & 295 & 36.2 & 252 & 34 & 217 & 37.5 & 0.928 \\
\hline \multirow[t]{2}{*}{ Facility ownership } & Faith-based & 537 & 25.3 & 212 & 23.0 & 183 & 25.6 & 142 & 27.7 & \\
\hline & Public & 1141 & 74.7 & 432 & 77.0 & 395 & 74.4 & 314 & 72.3 & 0.123 \\
\hline \multirow{2}{*}{$\begin{array}{l}\text { Start of performance based } \\
\text { financing }\end{array}$} & 2004-2006 & 919 & 55.2 & 363 & 55.7 & 332 & 59.0 & 224 & 50.1 & \\
\hline & $2007-2008$ & 759 & 44.9 & 281 & 44.3 & 246 & 41.0 & 232 & 49.9 & 0.628 \\
\hline \multicolumn{2}{|c|}{ Home visits support for PLWHA ${ }^{e}$} & 887 & 50.9 & 333 & 49.6 & 304 & 52.6 & 250 & 50.6 & 0.942 \\
\hline
\end{tabular}

${ }^{\mathrm{a}} \mathrm{VCT}=$ Voluntary Counseling and Testing services; ${ }^{\mathrm{b}} \mathrm{PMTCT}=$ Prevention of Mother-to-Child HIV Transmission.

Includes Tuberculosis clinics [n $=17]$, outpatient services $[n=45]$ and other modes of admission $[n=107]$.

${ }^{d}$ Adults missing data on WHO stage at ART initiation $[n=35,2.1 \%]$.

ePLWHA = Persons Living with HIV/AIDS.

WHO stage I or II at the time of ART initiation, with only $2.4 \%$ missing WHO stage data at ART initiation. CD4+ counts at ART initiation were available for $84.9 \%$ of the population. Among those with available data, median CD4+ count was 206 cells/ $\mu \mathrm{L}$ [IQR 137-286], and 37.0\% had CD4+ count less than 200cells/ $\mu \mathrm{L}$ at the time of ART initiation. Of note, the median CD4 count at ART initiation among adults who started ART as in-patients was 74 cells $/ \mu \mathrm{L}$ [IQR 34-194] vs 218 cells/ $\mu \mathrm{L}$ [IQR 150-288] among patients enrolled from VCT and 256 cells/ $\mu \mathrm{L}$ [IQR 177-313] among patients enrolled from PMTCT clinics. The majority of the population initiated stavudine [58.9\%] and zidovudine [40.9\%] in the first-line regimen, all combined with lamivudine and nevirapine [90.3\%] or efavirenz [9.1\%].

Half the population attended health facilities located in rural areas [50.0\%], and the majority attended health centers [64.2\%, vs $35.8 \%$ at hospitals]; and public government 
facilities [74.7\%, vs $25.3 \%$ at faith based health facilities]. All health facilities had performance based financing Nearly half [44.9\%] of the population attended health facilities where performance based financing had been introduced more recently [2007-2008 vs. 2004-2006] and half attended health facilities where home visit support services for patients who miss health facility visits were available [50.9\%].

When comparing the population by time of ART initiation, the population who initiated ART 6 and 12 months prior to data collection had a higher proportion of older adults [36 years and older], adults with WHO Stage I and II at ART initiation, and adults with CD4+ count above 200 cells $/ \mu \mathrm{L}$ at ART initiation, than the population who initiated ART 18 months prior to data collection. Stavudine use in the initial ART regimen declined from $83.3 \%$ to $65.3 \%$ and $34.1 \%$ for adults who had initiated ART 18, 12 and 6 months previously, while zidovudine use increased from $16.6 \%$ to $34.1 \%$ and to $65.8 \%$ respectively.

Of the population that initiated ART, 5.5\% transferred out to other health facilities. Of the remaining population, attrition was observed among 6.8\%, with $2.9 \%$ documented to have died and 3.9\% lost to follow-up [Table 2]. Attrition among adults who had initiated ART 6, 12 and 18 previously was $3.5 \%, 8.8 \%$ and $8.8 \%$ respectively. The population attrition rate was 7.5/100 PY, with deaths accounting for 3.2/100 PY and loss to follow-up 4.3/100PY [Table 2]. Attrition rates among adults who had initiated ART 6, 12 and 18 previously were 6.9/100 PY, 9.1/100 PY and 6.4/100 PY respectively.

Table 3 displays patient- and health facility-level characteristics associated with attrition in the bivariate and multi-variable analyses adjusting for various demographic, clinical and site characteristics. The adjusted hazard ratio [aHR] for attrition was highest for adults enrolled from in-patient wards: aHR 4.2 [95\% CI: 3.0-5.7]; and PMTCT services: aHR 2.2 [95\% CI: 1.6-3.0], compared to those enrolled from VCT services. Compared to adults who initiated ART 18 months earlier, adults who initiated ART 12 months earlier had higher hazard of attrition: aHR 1.8 [95\% CI: 1.3-2.5]; but no significant difference was observed with adults who had initiated ART in the previous 6 months: aHR 1.3 [95\% CI: $0.9-1.9$ ]. A higher hazard of attrition was also observed among men: aHR 1.4 [95\% CI: 1.0-1.8] than women; and adults attending urban health facilities: aHR 1.4 [95\% CI: 1.1-1.8] compared to those attending rural facilities.

The hazard of attrition was lower among adults whose CD4+ count at ART initiation was 200 cells/ $\mu \mathrm{L}$ or greater, aHR 0.8 [95\% CI: 0.6-1.0], compared to those who initiated ART with CD4+ counts below 200 cells $/ \mu \mathrm{L}$. Lower attrition hazard was also observed among adults who attended health facilities that had longer-standing performance- based financing [since 2004-2006], aHR 0.8 [95\% CI: 0.6-0.9], compared to patients attending health facilities where performance based financing had began more recently [2007-2008]. Age, initial ART regimen, level of health facility and availability of home visit services were not significantly associated with attrition in adjusted analyses.

\section{Discussion}

We assessed levels of attrition 6, 12 and 18 months following ART initiation among a nationally representative sample of adults receiving HIV services in Rwanda. We estimated overall population attrition to be $6.8 \%$ and the attrition rate as 7.5/100 PY. Lowrance et al., who explored this question in the early phase of the Rwanda ART program [2004-2005], reported attrition of $6.7 \%$ of patients at 6 months and $9.5 \%$ at 12 months on ART [13]. We found much lower attrition at 6 months, 3.5\%, and approximately the same attrition at 12 months, $8.8 \%$, in 2007-2008, suggesting a significant reduction in attrition at the 6 months following ART initiation. Our results tally with more recent findings using a significantly larger sample in two regions of Rwanda [17]. This is an important finding because the risk of attrition tends to be highest immediately after ART initiation, and is usually due to high mortality within this time period [18-20]. These findings may reflect the benefits of initiating ART earlier in HIV disease, as the median CD4+ count at ART initiation in our sample was 65 cells $/ \mu \mathrm{L}$, higher than that observed by Lowrance et al.

While Lowrance et al. observed that death and LTF contributed equally to attrition in the early phase of ART scale-up in Rwanda, our data indicate that LTF increasingly accounts for the majority of attrition. This may reflect deteriorating ascertainment and documentation of deaths as the ART program expands, and an increase in undocumented transfers as ART services are decentralized [20-22]. Stronger linkages and feedback between communities and health facilities [to report deaths] and between health facilities [to report transfers] could result in more accurate estimations of true loss to follow-up, mortality, and transfers and thus more complete assessment of the ART program impact.

While the level of attrition observed in our sample was in-line with other findings from Rwanda [13,14,23,17], it is substantially lower than that observed in other programs within the East African region, which report attrition in the range of $18 \%$ to $40 \% 12$ months after ART initiation [24-28]. Multiple factors may be contributing to the low attrition in ART programs in Rwanda. First, the median CD4+ count at ART initiation in our population was significantly higher than has been observed in other countries $[18,25,29,30]$, and could account for this association. Our results also showed that CD $4+$ counts $>200 / \mu \mathrm{L}$ were associated with a $20 \%$ reduction in attrition. Notably, 
Table 2 Proportion and rate of attrition and transfers per 100 person years: overall and by time on ART

\begin{tabular}{|c|c|c|c|c|c|c|c|c|c|c|c|c|}
\hline \multirow[b]{5}{*}{ Proportions: } & & & & \multicolumn{9}{|c|}{ Time on ART prior to data collection } \\
\hline & \multicolumn{3}{|c|}{ Overall (all adults) } & \multicolumn{3}{|c|}{6 months on ART } & \multicolumn{3}{|c|}{12 months on ART } & \multicolumn{3}{|c|}{18 months on ART } \\
\hline & \multicolumn{3}{|c|}{1509 person years } & \multicolumn{3}{|c|}{330 person years } & \multicolumn{3}{|c|}{559 person years } & \multicolumn{3}{|c|}{619 person years } \\
\hline & \multicolumn{3}{|c|}{1678 adults } & \multicolumn{3}{|c|}{644 adults } & \multicolumn{3}{|c|}{578 adults } & \multicolumn{3}{|c|}{456 adults } \\
\hline & $n$ & Weighted \% & $95 \% \mathrm{Cl}$ & $\mathrm{n}$ & Weighted \% & $95 \% \mathrm{Cl}$ & $\mathrm{n}$ & Weighted \% & $95 \% \mathrm{Cl}$ & $\mathrm{n}$ & Weighted \% & $95 \% \mathrm{Cl}$ \\
\hline Attrition & 135 & 6.8 & {$[6.0-7.8]$} & 25 & 3.5 & {$[2.7-4.5]$} & 58 & 8.8 & {$[7.1-10.9]$} & 52 & 8.8 & {$[7.9-11.4]$} \\
\hline Recorded death & 48 & 2.9 & {$[2.4-3.5]$} & 13 & 1.6 & {$[1.1-2.3]$} & 16 & 2.9 & {$[2.0-4.1]$} & 19 & 4.6 & {$[3.5-6.0]$} \\
\hline Lost to follow-up & 87 & 3.9 & {$[3.4-4.5]$} & 12 & 1.9 & {$[1.3-2.7]$} & 42 & 5.9 & {$[5.0-7.0]$} & 33 & 4.2 & {$[3.2-5.6]$} \\
\hline Transfer out & 99 & 5.5 & {$[4.5-6.8]$} & 34 & 6.1 & {$[4.5-8.2]$} & 26 & 3.6 & {$[2.5-5.3]$} & 39 & 6.9 & {$[4.8-9.8]$} \\
\hline Retained on ART & 1444 & 87.7 & {$[86.0-89.2]$} & 585 & 90.4 & {$[88.4-92.2]$} & 494 & 87.6 & {$[84.7-90.0]$} & 365 & 84.3 & {$[80.4-87.5]$} \\
\hline Rates: & No. & Weighted rate & $95 \% \mathrm{Cl}$ & No. & Weighted rate & $95 \% \mathrm{Cl}$ & No. & Weighted rate & $95 \% \mathrm{Cl}$ & No. & Weighted rate & $95 \% \mathrm{Cl}$ \\
\hline Attrition & 135 & 7.5 & {$[6.1-9.3]$} & 25 & 6.9 & {$[4.3-11.9]$} & 58 & 9.1 & {$[6.6-12.7]$} & 52 & 6.4 & {$[4.6-9.2]$} \\
\hline Recorded death & 48 & 3.2 & {$[2.3-4.5]$} & 13 & 3.2 & {$[1.7-6.9]$} & 16 & 2.9 & {$[1.6-5.6]$} & 19 & 3.3 & {$[2.0-5.9]$} \\
\hline Lost to follow-up & 87 & 4.3 & {$[3.3-5.6]$} & 12 & 3.7 & {$[1.8-8.8]$} & 42 & 6.1 & {$[4.2-9.2]$} & 33 & 3.1 & {$[2.0-4.9]$} \\
\hline Transfer out & 99 & 6.0 & {$[4.7-7.8]$} & 34 & 12.1 & {$[7.9-19.4]$} & 26 & 3.7 & {$[2.4-6.3]$} & 39 & 5.0 & {$[3.4-7.5]$} \\
\hline Retained on ART & 1444 & 95.7 & {$[92.8-98.7]$} & 585 & 179.5 & {$[174.5-184.6]$} & 494 & 90.3 & {$[88.1-92.6]$} & 365 & 61.1 & {$[59.5-62.7]$} \\
\hline
\end{tabular}


Table 3 Crude and adjusted Cox proportional models for the hazard of attrition (death or loss to follow-up)

\begin{tabular}{|c|c|c|c|c|c|c|c|}
\hline & \multirow[b]{2}{*}{ Attrition $\mathrm{N}$} & \multicolumn{3}{|c|}{ Bivariate analysis } & \multicolumn{3}{|c|}{ Multi-variable model $n=1,678$} \\
\hline & & HR of attrition & $95 \% \mathrm{Cl}$ & p-value & aHR of attrition & $95 \% \mathrm{Cl}$ & $\mathrm{p}$-value \\
\hline \multicolumn{8}{|c|}{ Time on ART prior to data collection } \\
\hline 18 months on ART & 52 & Ref & & & Ref & & \\
\hline 6 months on ART & 25 & 1.1 & {$[0.8-1.7]$} & 0.517 & 1.3 & {$[0.9-1.9]$} & 0.190 \\
\hline 12 months on ART & 58 & 1.7 & {$[1.2-2.4]$} & 0.003 & 1.8 & {$[1.3-2.5]$} & 0.000 \\
\hline \multicolumn{8}{|l|}{ Age } \\
\hline $18-25$ years & 27 & Ref & & & Ref & & \\
\hline $26-35$ years & 48 & 0.8 & {$[0.5-1.2]$} & 0.195 & 0.8 & {$[0.5-1.3]$} & 0.395 \\
\hline $36-45$ years & 44 & 0.9 & {$[0.6-1.2]$} & 0.318 & 1.0 & {$[0.7-1.4]$} & 0.864 \\
\hline $46+$ years & 16 & 0.6 & {$[0.4-0.9]$} & 0.014 & 0.8 & {$[0.5-1.3]$} & 0.379 \\
\hline \multicolumn{8}{|l|}{ Gender } \\
\hline Females & 48 & Ref & & & Ref & & \\
\hline Males & 87 & 1.3 & {$[1.0-1.6]$} & 0.066 & 1.4 & {$[1.0-1.8]$} & 0.027 \\
\hline \multicolumn{8}{|l|}{ Source of referral to ART clinic } \\
\hline Voluntary Counseling and Testing & 70 & Ref & & & Ref & & \\
\hline PMTCT services & 35 & 2.1 & {$[1.6-2.7]$} & 0.000 & 2.2 & {$[1.6-3.0]$} & 0.000 \\
\hline In-patient ward & 15 & 4.1 & {$[3.0-5.6]$} & 0.000 & 4.2 & {$[3.0-5.7]$} & 0.000 \\
\hline Other & 15 & 1.6 & {$[1.2-2.2]$} & 0.001 & 1.5 & {$[1.1-2.0]$} & 0.004 \\
\hline \multicolumn{8}{|c|}{ CD4+ count at ART initiation (cells $/ \mu \mathrm{L}$ ) } \\
\hline $0-199$ & 69 & Ref & & & Ref & & \\
\hline $200+$ & 45 & 0.7 & {$[0.5-0.9]$} & 0.005 & 0.8 & {$[0.6-1.0]$} & 0.031 \\
\hline Missing & 21 & 1.0 & {$[0.7-1.3]$} & 0.763 & 1.0 & {$[0.8-1.3]$} & 0.811 \\
\hline \multicolumn{8}{|l|}{ Initial ART regimen } \\
\hline Stavudine containing & 80 & Ref & & & Ref & & \\
\hline Zidovudine containing & 54 & 1.1 & {$[0.9-1.3]$} & 0.423 & 1.0 & {$[0.8-1.2]$} & 0.944 \\
\hline Tenofovir containing & 1 & 1.6 & {$[0.7-3.6]$} & 0.240 & 1.7 & {$[0.8-3.9]$} & 0.165 \\
\hline \multicolumn{8}{|l|}{ Location } \\
\hline Rural & 32 & Ref & & & Ref & & \\
\hline Urban & 103 & 1.5 & {$[1.1-2.0]$} & 0.005 & 1.4 & {$[1.1-1.8]$} & 0.013 \\
\hline \multicolumn{8}{|l|}{ Facility level* } \\
\hline Hospitals & 52 & Ref & & & Ref & & \\
\hline Health centers & 83 & 0.9 & {$[0.7-1.2]$} & 0.483 & 0.8 & {$[0.6-1.1]$} & 0.226 \\
\hline \multicolumn{8}{|c|}{ Start of performance based financing } \\
\hline 2007-2008 & 85 & Ref & & & Ref & & \\
\hline 2004-2006 & 50 & 0.9 & {$[0.6-1.2]$} & 0.239 & 0.8 & {$[0.6-0.9]$} & 0.016 \\
\hline \multicolumn{8}{|c|}{ Home support visits for PLWHA available } \\
\hline No & 60 & Ref & & & Ref & & \\
\hline Yes & 75 & 1.2 & {$[0.9-1.6]$} & 0.415 & 1.2 & {$[1.0-1.6]$} & 0.097 \\
\hline
\end{tabular}

*Facility ownership variable (public vs faith based) excluded from the model due to collinearity with facility level variable.

patients whose CD4+ counts at ART initiation were missing had similar hazard of attrition to the patients with the lowest CD4+ counts. This finding suggests that patients whose $\mathrm{CD} 4+$ counts are not assessed and recorded at ART initiation may be as vulnerable to attrition as the sickest patients. Secondly, adults in the Rwanda ART program tend to have high adherence to ART [31,32] which in turn can reduce mortality, and thus attrition. This is further evidenced by adherence and viral load assessments conducted on a subset of participants in this analysis which revealed that overall [combining adults on ART 6, 12 and 18 months], 94\% and 78\% took 100\% of 
their medication in the 3 and 30 days preceding the interview, and $83 \%$ had viral load under 40 copies $/ \mathrm{mL}$ at the time of interview [15].

The most significant factor associated with increased hazard of attrition in our study was starting ART while admitted within an in-patient ward. This finding has been observed by others [33], and is likely due to high mortality in this severely ill group and LTF due to undocumented deaths [20,34]. Indeed, the median CD4 count at ART initiation among in-patients was about a third of observed among other study participants. Recent recommendations by WHO and the Rwanda Ministry of Health [35-37], which endorse ART initiation at higher CD4 counts $[350$ cells $/ \mu / L$ and more recently 500 cells/ $\mu / L]$, could result in adults initiating ART earlier in HIV disease, and thus lower attrition. Enrolling from PMTCT services was also associated with high attrition. This has been observed in a number of African programs [38,39], and is a challenge worth addressing as countries begin to implement for life-long ART for all pregnant and breastfeeding women. The finding that men had higher attrition than women is not uncommon in African HIV treatment programs [40-44]; this is a high risk group that requires targeted interventions to minimize attrition.

Adults who attended health facilities with a longer duration of performance based financing had a lower hazard attrition in our analysis. Although our analysis lacked data to comparatively examine attrition at facilitates without performance based financing, implementation of performance based financing is perceived as a strong motivator for provision of better health care services [45-47], and may have contributed to improvements in patient outcomes at these health facilities clinics. It is possible that sites that initiated performance based financing earlier had other unmeasured characteristics that influenced attrition outcomes, and further research should examine the specific impact of this strategy on lowering attrition in African ART programs.

Our study did not find a correlation between home visits and attrition, a finding in line with results of a multi-country ecological study examining the impact of site-level factors on attrition [48]. Whereas it has been observed that home-visits can be associated with better retention [49], it is likely that in our setting of high retention, the impact of home visits was minimal, particularly if targeted to patients with high risk of attrition that may have insurmountable barriers to returning to care.

Our study had a number of strengths. We had a large sample of adults drawn from a nationally representative sample of adults on ART, and there was representation from different types of health facilities in various settings. The study was conducted in one of the first few African countries to achieve universal ART access. In multivariate analyses, we explored associations between both patient- and health facility- level factors and attrition. A limitation to note, however, is that the study lacked sufficient power to examine factors associated with death and LTF in separate models or present results stratified by time on ART. Despite this, the results effectively demonstrate the low attrition rates and some key factors associated with the risk of attrition for the overall population.

\section{Conclusion}

Our results suggest sustained low attrition in the Rwanda national ART program in the context of significant expansion in the number of clinics providing HIV care and treatment services and the number of patients on ART. Loss to follow-up was the more significant contributor to attrition suggesting that better ascertainment and documentation of deaths and patient transfers may be necessary. In this context of universal ART access, specific groups remain at risk of high attrition [including inpatients, men, PMTCT clients and adults attending urban facilities] and require targeted interventions to further reduce attrition. Performance-based financing could be a useful tool in minimizing attrition in this context.

\section{Competing interests}

The authors declare that they have no competing interests.

\section{Authors' contributions}

Conceived and designed the analysis: $B E, H N B$. Substantially contributed to protocol development and data collection: PB, HNB, BE, VM, AA, DN Analyzed the data: AJ, HNB, BE. Wrote the paper: HNB, AJ. Critically revised the paper: $B E, P B, V M, A A, D N$. All authors reviewed and approved the final version.

\section{Acknowledgements}

We thank the participants and staff at the facilities included in the study for their participation; study co-investigators, collaborators and the field team. The work in this publication was supported by the United States President's Emergency Plan for AIDS Relief [PEPFAR] through the United States Centers for Disease Control and Prevention $[\mathrm{CDC}]$ under the terms of Cooperative Agreement Number U62/CCU222407 in partnership with the Global Fund to Fight AIDS, Tuberculosis and Malaria. The contents of this publication are solely the responsibility of the authors and do not necessarily represent the official views of PEPFAR, CDC or Global Fund.

\section{Author details}

${ }^{1}$ ICAP, Columbia University, Mailman School of Public Health, New York, New York, USA. ${ }^{2}$ Department of Epidemiology, Mailman School of Public Health, Columbia University, New York, New York, USA. ${ }^{3}$ Bill and Melinda Gates Foundation, Seattle, Washington, USA. ${ }^{4}$ Rwanda Biomedical Center [RBC], Ministry of Health, Kigali, Rwanda. ${ }^{5}$ Hunter College, City University of New York, New York, New York, USA.

Received: 29 March 2014 Accepted: 29 July 2014

Published: 29 August 2014

\section{References}

1. Bussmann H, Wester CW, Ndwapi N, Grundmann N, Gaolathe T, Puvimanasinghe J, Avalos A, Mine M, Seipone K, Essex M, Degruttola V, Marlink RG: Five-year outcomes of initial patients treated in Botswana's National Antiretroviral Treatment Program. AIDS 2008, 22(17):2303-2311.

2. Nglazi MD, Lawn SD, Kaplan R, Kranzer K, Orrell C, Wood R, Bekker LG: Changes in programmatic outcomes during 7 years of scale-up at a 
community-based antiretroviral treatment service in South Africa. J Acquir Immune Defic Syndr 2010, 56(1):e1-e8.

3. Cornell M, Grimsrud A, Fairall L, Fox MP, van Cutsem G, Giddy J, Wood R, Prozesky H, Mohapi L, Graber C, Egger M, Boulle A, Myer L: Temporal changes in programme outcomes among adult patients initiating antiretroviral therapy across South Africa, 2002-2007. AIDS 2010, 24(14):2263-2270.

4. Micek MA, Gimbel-Sherr K, Baptista AJ, Matediana E, Montoya P, Pfeiffer J, Melo A, Gimbel-Sherr S, Johnson W, Gloyd S: Loss to follow-up of adults in public HIV care systems in central Mozambique: identifying obstacles to treatment. J Acquir Immune Defic Syndr 2009, 52(3):397-405.

5. May M, Boulle A, Phiri S, Messou E, Myer L, Wood R, Keiser O, Sterne JA, Dabis F, Egger M: Prognosis of patients with HIV-1 infection starting antiretroviral therapy in sub-Saharan Africa: a collaborative analysis of scale-up programmes. Lancet 2010, 376(9739):449-457.

6. Boulle A, Van Cutsem G, Hilderbrand K, Cragg C, Abrahams M, Mathee S, Ford N, Knight L, Osler M, Myers J, Goemaere E, Coetzee D, Maartens G: Seven-year experience of a primary care antiretroviral treatment programme in Khayelitsha, South Africa. AIDS 2010, 24(4):563-572.

7. Fox MP, Rosen S: Patient retention in antiretroviral therapy programs up to three years on treatment in sub-Saharan Africa, 2007-2009: systematic review. Trop Med Int Health 2010, 15(Suppl 1):1-15.

8. Rosen S, Fox MP, Gill CJ: Patient retention in antiretroviral therapy programs in sub-Saharan Africa: a systematic review. PLoS Med 2007, 4(10):e298.

9. WHO, UNAIDS, UNICEF: Towards Universal Access: Scaling up priority HIV/ AIDS interventions in the health sector. Progress Report 2010. In Towards Universal Access. Geneva: WHO; 2010.

10. WHO, UNAIDS, UNICEF: Global HIV/AIDS Response: Epidemic update and health sector progress towards Universal Access Progress Report 2011. In Towards Universal Access. 2011. http://whqlibdoc.who.int/publications/ 2011/9789241502986_eng.pdf?ua=1.

11. Republic of Rwanda: Country Progress Report January 2008 - December 2009, United Nations General Assembly Special Session on HIV and AIDS. Kigali: National AIDS Control Commission (CNLS); 2010.

12. Ministry of Health Republic of Rwanda: Annual Report 2011-2012. Kigali: Ministry of Health; 2012.

13. Lowrance DW, Ndamage F, Kayirangwa E, Ndagije F, Lo W, Hoover DR Hanson J, Elul B, Ayaba A, Ellerbrock T, Rukundo A, Shumbusho F, Nash D, Mugabo J, Assimwe A: Adult clinical and immunologic outcomes of the national antiretroviral treatment program in Rwanda during 2004-2005. J Acquir Immune Defic Syndr 2009, 52(1):49-55.

14. Rich ML, Miller AC, Niyigena P, Franke MF, Niyonzima JB, Socci A, Drobac PC, Hakizamungu M, Mayfield A, Ruhayisha R, Epino H, Stulac S, Cancedda C, Karamaga A, Niyonzima S, Yarbrough C, Fleming J, Amoroso C, Mukherjee J, Murray M, Farmer P, Binagwaho A: Excellent clinical outcomes and high retention in care among adults in a community-based HIV treatment program in rural Rwanda. I Acquir Immune Defic Syndr 2011, 59(3):e35-e42

15. Elul B, Basinga P, Nuwagaba-Biribonwoha H, Saito S, Horowitz D, Nash D, Mugabo J, Mugisha V, Rugigana E, Nkunda R, Asiimwe A: High levels of adherence and viral suppression in a nationally representative sample of HIV-infected adults on antiretroviral therapy for 6, 12 and 18 months in Rwanda. PLoS One 2013, 8(1):e53586.

16. Centre de Traitement et de Recherche sur le SIDA: Guide d'utilisation des medicaments antiretroviraux chez l'adulte et l'enfant. Edited by Republique du Rwanda Ministère de la Santé. Kigali: Republique du Rwanda; 2003.

17. Mugisha V, Teasdale CA, Wang C, Lahuerta M, Nuwagaba-Biribonwoha $H$, Tayebwa E, Ingabire E, Ingabire P, Sahabo R, Twyman P, Abrams EJ, for the Identifying Optimal Models for HIV Care in Africa Rwanda Consortium: Determinants of mortality and loss to follow-up among adults enrolled in HIV care services in Rwanda. PLoS One 2014, 9(1):e85774.

18. Lahuerta M, Lima J, Elul B, Okamura M, Alvim MF, Nuwagaba-Biribonwoha H, Horowitz D, Fernandes R, Assan A, Abrams EJ, El-Sadr WM, Nash D: Patients enrolled in HIV care in Mozambique: baseline characteristics and follow-up outcomes. J Acquir Immune Defic Syndr 2011, 58(3):e75-e86.

19. Brinkhof MW, Dabis F, Myer L, Bangsberg DR, Boulle A, Nash D, Schechter M, Laurent C, Keiser O, May M, Sprinz E, Egger M, Anglaret X: Early loss of HIV-infected patients on potent antiretroviral therapy programmes in lower-income countries. Bull World Health Organ 2008, 86(7):559-567.
20. Geng EH, Bangsberg DR, Musinguzi N, Emenyonu N, Bwana MB, Yiannoutsos CT, Glidden DV, Deeks SG, Martin JN: Understanding reasons for and outcomes of patients lost to follow-up in antiretroviral therapy programs in Africa through a sampling-based approach. J Acquir Immune Defic Syndr 2009, 53(3):405-411.

21. Yu JK, Chen SC, Wang KY, Chang CS, Makombe SD, Schouten EJ, Harries AD: True outcomes for patients on antiretroviral therapy who are "lost to follow-up" in Malawi. Bull World Health Organ 2007, 85(7):550-554.

22. Weigel R, Hochgesang M, Brinkhof MW, Hosseinipour MC, Boxshall M, Mhango E, Nkwazi B, Tweya H, Kamlaka M, Chagwera F, Phiri S: Outcomes and associated risk factors of patients traced after being lost to follow-up from antiretroviral treatment in Lilongwe, Malawi. BMC Infect Dis 2011, 11:31.

23. Franke MF, Kaigamba F, Socci AR, Hakizamungu M, Patel A, Bagiruwigize $E$, Niyigena PC, Walker KD, Epino H, Binagwaho A, Mukherjee J, Farmer PE, Rich ML: Improved retention associated with community-based accompaniment for antiretroviral therapy delivery in rural Rwanda. Clin Infect Dis 2013, 56(9):1319-1326.

24. Somi G, Keogh SC, Todd J, Kilama B, Wringe A, van den Hombergh J, Malima K, Josiah R, Urassa M, Swai R, Zaba B: Low mortality risk but high loss to follow-up among patients in the Tanzanian national HIV care and treatment programme. Trop Med Int Health 2012, 17(4):497-506.

25. Assefa Y, Kiflie A, Tesfaye D, Mariam DH, Kloos H, Edwin W, Laga M, Van Damme W: Outcomes of antiretroviral treatment program in Ethiopia: retention of patients in care is a major challenge and varies across health facilities. BMC Health Serv Res 2011, 11:81.

26. Unge C, Sodergard B, Ekstrom AM, Carter J, Waweru M, llako F, Ragnarsson A, Thorson A: Challenges for scaling up ART in a resource-limited setting: a retrospective study in Kibera, Kenya. J Acquir Immune Defic Syndr 2009, 50(4):397-402.

27. Somi G, Matee M, Makene CL, Van Den Hombergh J, Kilama B, YahyaMalima Kl, Masako P, Sando D, Ndayongeje J, Rabiel B, Swai RO: Three years of HIV/AIDS care and treatment services in Tanzania: achievements and challenges. Tanzan J Health Res 2009, 11(3):136-143.

28. Bajunirwe F, Arts EJ, Tisch DJ, King CH, Debanne SM, Sethi AK: Adherence and treatment response among HIV-1-infected adults receiving antiretroviral therapy in a rural government hospital in Southwestern Uganda. J Int Assoc Physicians AIDS Care (Chic) 2009, 8(2):139-147.

29. Nash D, Katyal M, Brinkhof MW, Keiser O, May M, Hughes R, Dabis F, Wood R, Sprinz E, Schechter M, Egger M, ART-LINC Collaboration of leDEA: Long-term immunologic response to antiretroviral therapy in low-income countries: a collaborative analysis of prospective studies. AIDS 2008, 22(17):2291-2302.

30. Nash D, Wu Y, Elul B, Hoos D, El Sadr W: Program-level and contextual-level determinants of low-median CD4+ cell count in cohorts of persons initiating ART in eight sub-Saharan African countries. AIDS 2011, 25(12):1523-1533.

31. Demeester R, Omes C, Karasi JC, Schneider S, Mugabo J, Maliboli MJ, Arendt $\mathrm{V}$ : Adherence to first-line antiretroviral regimens in Rwanda. J Acquir Immune Defic Syndr 2005, 40(1):113-114.

32. Musiime S, Muhairwe F, Rutagengwa A, Mutimura E, Anastos K, Hoover DR, Qiuhu S, Munyazesa E, Emile I, Uwineza A, Cowan E: Adherence to highly active antiretroviral treatment in HIV-infected Rwandan women. PLoS One 2011, 6(11):e27832.

33. Boyles TH, Wilkinson LS, Leisegang R, Maartens G: Factors influencing retention in care after starting antiretroviral therapy in a rural South African programme. PLoS One 2011, 6(5):e19201.

34. Dalal RP, Macphail C, Mqhayi M, Wing J, Feldman C, Chersich MF, Venter WD: Characteristics and outcomes of adult patients lost to follow-up at an antiretroviral treatment clinic in johannesburg, South Africa. J Acquir Immune Defic Syndr 2008, 47(1):101-107.

35. WHO: Antiretroviral therapy for HIV infection in adults and adolescents in resource-limited settings: Towards universal access, Recommendations for a public health approach. In HIV/AIDS Programme: Strengthening Health Services to Fight HIV/AIDS. 2010th edition. Edited by WHO. Geneva: WHO; 2010.

36. World Health Organisation (WHO): Consolidated guidelines on the use of antiretroviral drugs for treating and preventing HIV infection: recommendations for a public health approach. In HIV/AIDS Programme. 2013th edition. Edited by WHO. Geneva: WHO; 2013.

37. Rwanda Biomedical Centre (RBC): HIV National Guidelines 2011: Main Changes. Edited by Institute of HIV/AIDS Disease Prevention and Control. Kigali: RBC; 2012. 
38. Baltazary G, Akarro RR, Mussa AS: Some factors associated with non-adherence to antiretroviral therapy (ART) in people living with HIV/AIDS (PLHA) in Tanzania: a case study of Dar es Salaam region. East Afr J Public Health 2012, 8(4):237-246.

39. Nachega JB, Uthman OA, Anderson J, Peltzer K, Wampold S, Cotton MF, Mills EJ, Ho YS, Stringer JS, McIntyre JA, Mofenson LM: Adherence to antiretroviral therapy during and after pregnancy in low-income, middle-income, and high-income countries: a systematic review and meta-analysis. AIDS 2012, 26(16):2039-2052.

40. Charurat M, Oyegunle M, Benjamin R, Habib A, Eze E, Ele P, Ibanga I, Ajayi S, Eng M, Mondal P, Gebi U, Iwu E, Etiebet MA, Abimiku A, Dakum P, Farley J, Blattner W: Patient retention and adherence to antiretrovirals in a large antiretroviral therapy program in Nigeria: a longitudinal analysis for risk factors. PLoS One 2010, 5(5):e10584.

41. Hawkins C, Chalamilla G, Okuma J, Spiegelman D, Hertzmark E, Aris E, Ewald T, Mugusi F, Mtasiwa D, Fawzi W: Sex differences in antiretroviral treatment outcomes among HIV-infected adults in an urban Tanzanian setting. AIDS 2011, 25(9):1189-1197.

42. Kranzer K, Lewis JJ, Ford N, Zeinecker J, Orrell C, Lawn SD, Bekker LG, Wood R: Treatment interruption in a primary care antiretroviral therapy program in South Africa: cohort analysis of trends and risk factors. J Acquir Immune Defic Syndr 2010, 55(3):e17-e23.

43. Maskew M, Brennan AT, Westreich D, McNamara L, Macphail AP, Fox MP: Gender differences in mortality and CD4 count response among virally suppressed HIV-positive patients. J Womens Health (Larchmt) 2013, 22(2):113-120.

44. Mills EJ, Bakanda C, Birungi J, Chan K, Hogg RS, Ford N, Nachega JB, Cooper $\mathrm{CL}$ : Male gender predicts mortality in a large cohort of patients receiving antiretroviral therapy in Uganda. J Int AIDS Soc 2011, 14:52.

45. Low-Beer D, Afkhami H, Komatsu R, Banati P, Sempala M, Katz I, Cutler J, Schumacher P, Tran-Ba-Huy R, Schwartlander B: Making performance-based funding work for health. PLoS Med 2007, 4(8):e219.

46. Priedeman SM, Curtis SL, Basinga P, Angeles G: An equity analysis of performance-based financing in Rwanda: are services reaching the poorest women? Health Policy Plan 2013, 28(8):825-837.

47. Basinga P, Gertler PJ, Binagwaho A, Soucat ALB, Sturdy J, Vermeersch CMJ: Effect on maternal and child health services in Rwanda of payment to primary health-care providers for performance: an impact evaluation. Lancet 2011, 377:1421-1428.

48. Lamb MR, El-Sadr WM, Geng E, Nash D: Association of adherence support and outreach services with total attrition, loss to follow-up, and death among ART patients in sub-Saharan Africa. PLoS One 2012, 7(6):e38443.

49. Messou E, Chaix ML, Gabillard D, Minga A, Losina E, Yapo V, Kouakou M, Danel C, Sloan C, Rouzioux C, Freedberg KA, Anglaret X: Association between medication possession ratio, virologic failure and drug resistance in HIV-1-infected adults on antiretroviral therapy in Cote d'Ivoire. J Acquir Immune Defic Syndr 2010, 56(4):356-364.

doi:10.1186/1471-2458-14-889

Cite this article as: Nuwagaba-Biribonwoha et al.: Low risk of attrition among adults on antiretroviral therapy in the Rwandan national program: a retrospective cohort analysis of 6,12 , and 18 month outcomes. BMC Public Health 2014 14:889.

\section{Submit your next manuscript to BioMed Central and take full advantage of:}

- Convenient online submission

- Thorough peer review

- No space constraints or color figure charges

- Immediate publication on acceptance

- Inclusion in PubMed, CAS, Scopus and Google Scholar

- Research which is freely available for redistribution

Submit your manuscript at www.biomedcentral.com/submit 